\title{
Efektivitas Peran Pustakawan Sebagai Mitra Pemustaka Menemukan Sumber Pustaka untuk Penelitian
}

\author{
Mariatul Qibthiyyah \\ UPT Perpustakaan Universitas Lambung Mangkurat \\ E-mail: mariatul.qibthiyyah@ulm.ac.id
}

\begin{abstract}
The purpose of this study is to describe the effectiveness of the role of librarians as friends in finding library sources for research. The design is a mixed method with the Triangulation Design procedure: Validating Quantitative Data Model. In this model, researchers will collect quantitative data and qualitative data. The next stage is to carry out further analysis by validating the results of quantitative analysis using qualitative results. The population in the study were all lecturers at Lambung Mangkurat University. The sample to determine the effectiveness of the role of librarians in research, namely 100 lecturers. Data were collected by filling out a questionnaire to answer all problem formulations. Also supported by interviewing lecturers to validate the results of filling out a questionnaire about the role of the librarian as a place to find library sources for research. The results of this study is that $54.49 \%$ of researchers agree that librarians are effective as friends in finding sources of literature for research. $33.91 \%$ of researchers strongly agree. While a small proportion of researchers, namely $0.87 \%$ and $0.58 \%$, respectively, stated that they disagreed and disagreed with the statement. The conclusion of this research was the librarian's role has been effective as a friend in finding library resources for research.
\end{abstract}

Keywords: Effectiveness; Library; Research

\begin{abstract}
Abstrak
Tujuan dari penelitian ini adalah mendeskripsikan efektivitas peran pustakawan sebagai teman menemukan sumber pustaka untuk penelitian. Penelitian ini adalah penelitian survei. Populasi dalam penelitian adalah seluruh dosen Universitas Lambung Mangkurat. Sampel untuk mengetahui efektivitas peran pustakawan dalam penelitian, yakni 100 dosen. Data dikumpulkan melalui pengisian kuisioner untuk menjawab semua rumusan masalah. Setelah itu, didukung dengan mewawancarai dosen untuk memvalidasi hasil pengisian kuisioner tentang peran pustakawan sebagai tempat menemukan sumber pustaka untuk penelitian. Hasil penelitian ini adalah $54,49 \%$ peneliti setuju bahwa pustakawan efektif sebagai teman
\end{abstract}

Tik Ilmeu : Jurnal Ilmu Perpustakaan dan Informasi

IAIN Curup | p-issn: 2580-3654; e-issn:2580-3662

DOI: $10.29240 /$ tik.v5i2.1953 
menemukan sumber pustaka untuk penelitian. 33, 91\% peneliti manyatakan sangat setuju. Sementara sebagian kecil peneliti yakni 0, 87\% dan 0,58\% peneliti secara berturut-turut menyatakan bahwa mereka kurang setuju dan tidak setuju dengan pernyataan tersebut. Simpulan dari penelitian ini adalah bahwa peran pustakawan telah efektif sebagai mitra pemustaka dalam menemukan sumber pustaka untuk penelitian.

Kata Kunci: Efektivitas; Pustakawan; Penelitian.

\section{A. PENDAHULUAN}

Pustakawan adalah memiliki tupoksi, tanggung jawab, wewenang dan hak untuk menjalankan hal-hal yang berkaitan dengan kepustakawanan. Kepustakawanan adalah kegiatan ilmiah dan professional yang meliputi pengelolaan perpustakaan, pelayanan perpustakaan, dan pengembangan sistem kepustakawanan (Peraturan Kepala Perpustakaan Nasional Republik Indonesia Nomor 11 Tahun 2015 Tentang Petunjuk Teknis Jabatan Fungsional Pustakawan Dan Angka Kreditnya, 2015). Pustakawan memiliki andil untuk proses pengolahan informasi serta menjadi tonggak utama dalam hal menyediakan dan menyampaikan berbagai informasi tersebut bagi pemustaka (Asmad \& Mathar, 2015).

Tugas pokok Pustakawan adalah kegiatan di bidang kepustakawanan yang meliputi Pengelolaan Perpustakaan, Pelayanan Perpustakaan, dan Pengembangan Sistem Kepustakawanan yang dilakukan oleh setiap Pustakawan sesuai jenjang jabatannya (Peraturan Kepala Perpustakaan Nasional Republik Indonesia Nomor 11 Tahun 2015 Tentang Petunjuk Teknis Jabatan Fungsional Pustakawan Dan Angka Kreditnya, 2015). Azwar \& Kaharuddin (2016) menyatakan bahwa perpustakaan yang didukung oleh keberadaan pustakawan mempunyai peranan besar dalam pendidikan khususya dalam menyediakan berbagai sumber pustaka, menyediakan tempat membaca bagi pengunjung dan menatanya dengan baik Perpustakaan dapat meningkatkan proses penelitian secara berkesinambungan karena perpustakaan menyediakan berbagai referensi.

Perguruan tinggi berkewajiban menyelenggarakan penelitian sebagaimana diamanahkan oleh Undang-undang Nomor 20 Tahun 2003 Tentang Sistem Pendidikan Nasional. Penelitian adalah salah satu tridharma perguruan tinggi yang harus dilaksanakan oleh dosen (Johan \& Ahmalia, 2019; Simanjuntak \& Wahyanti, 2021). Penelitian perguruan tinggi diarahkan untuk mengembangkan ilmu pengetahuan dan teknologi (Suryani, 2018). Penelitian ini harus diawali dengan analisis harapan dan permasalahan yang 
ada di lapangan. Oleh karena itu, penelitian harus memeiliki sumber referensi ilmiah yang kuat untuk menyelidiki berbagai gejala permasalahan serta menentukan solusinya.

Salah satu wadah untuk menemukan berbagai buku dan referensi ilmiah adalah perpustakaan. Perpustakaan turut menyediakan layanan terhadap tridharma perguruan tinggi (N. Kurniawati et al., 2012; Mujab et al., 2015) yakni dengan cara penyediaan, pengorganisasian, dan memberikan pelayanan kepada pengguna perpustakaan (M.Reza Rokan, 2017). Agar pelaksanaan pendidikan terutama kegiatan akademik civitas dapat berdaya guna dan berhasil guna, perpustakaan perguruan tinggi menempati kedudukan yang sentral dan strategis dalam perannya mewujudkan kegiatan Tri Dharma Perguruan Tinggi (Suwena, 2012).

Pustakawan dikatakan efektif dalam melaksanakan tugasnya jika pemustaka berhasil menemukan dan memanfaatkan Sumber Pustaka (Istiana, 2019; Qibthiyyah, 2020). Dosen memerlukan jasa dan layanan dari pustakawan yang efektif untuk proses penelitian. Efektivitas peran pustakawan dalam membantu pemustaka untuk menemukan Sumber Pustaka sangat menentukan kualitas dari Perpustakaan tersebut. Oleh karena itu, perlu di pelajari lebih lanjut bagaimana efektivitas peran pustakawan dalam membantu pemustaka untuk menemukan aneka referensi ilmiah.

Beberapa penelitian tentang peran pustakawan dalam mendukung dosen melaksanakn tridharma pendidikan telah dilaksanakan (Hapsari, 2017; A. Kurniawati \& Setyadi, 2019; Prabowo, 2018). Penelitian tersebut belum mengukur secara langsung bagaimana efektivitas peran pustakawan sebagai mitra pemustaka. Penelitian tentang peran pustakawan di UPT Perpustakaan ULM dalam bidang penelitian belum pernah dikaji sebelumnya oleh peneliti lain. Begitu juga kajian khusus tentang kaitannya terhadap proses penelitian, juga belum pernah dikaji. Tujuan dari penelitian ini adalah mendeskripsikan efektivitas pustakawan sebagai mitra pemustaka dalam menemukan sumber pustaka untuk penelitian. Rumusan masalah dari penelitian ini adalah bagaimana efektivitas pustakawan sebagai teman menemukan sumber pustaka untuk penelitian.

\section{Metode}

Penelitian ini menggunakan jenis penelitian survey. Populasi yang diangkat dalam pengumpulan data adalah seluruh dosen ULM. Sampel untuk mengambil data kuantitatif adalah 100 dosen. Sampel untuk wawancara adalah 10 dosen yang pilih acak dari sampel kuantitatif. Data dikumpulkan melalui pengisian kuisioner untuk menjawab semua rumusan masalah tentang 
peran pustakawan sebagai tempat menemukan sumber pustaka untuk penelitian. Data dianalisis dengan menggunakan persentase rerata. Data akan disajikan dalam bentuk deskriptif dan akan disajikan bentuk grafik dan plot yang didukung oleh deskripsi kualitatifnya.

\section{B. HASIL DAN PEMBAHASAN}

\section{Efektivitas Pustakawan Sebagai Mitra Pemustaka dalam Menemukan Sumber Pustaka Untuk Penelitian}

Kriteria yang harus dimiliki oleh pustakawan perguruan tinggi pada era global antara lain : (1) Memiliki Pendidikan dan Ketrampilan Tentang Kepustakawanan, (2) Memiliki Ketrampilan Pemanfaatan Teknologi Informasi, (3) Memiliki Ketrampilan Bahasa, (4) Mengetahui Kebutuhan Pemustaka, dan (5) Sense of Media. Lima komponen ini lah yang menjadi indikator untuk mengetahui efektivitas peran pustakawan sebagai mitra pemustaka dalam menemukan sumber pustaka untuk penelitian.

Data hasil Survei dianalisis sesuai dengan indikator dari efektivitas peran pustakawan ULM terhadap penelitian di ULM. Berikut ini adalah data hasil survei kepada para dosen:

1. Memiliki Pendidikan dan Ketrampilan Tentang Kepustakawanan,

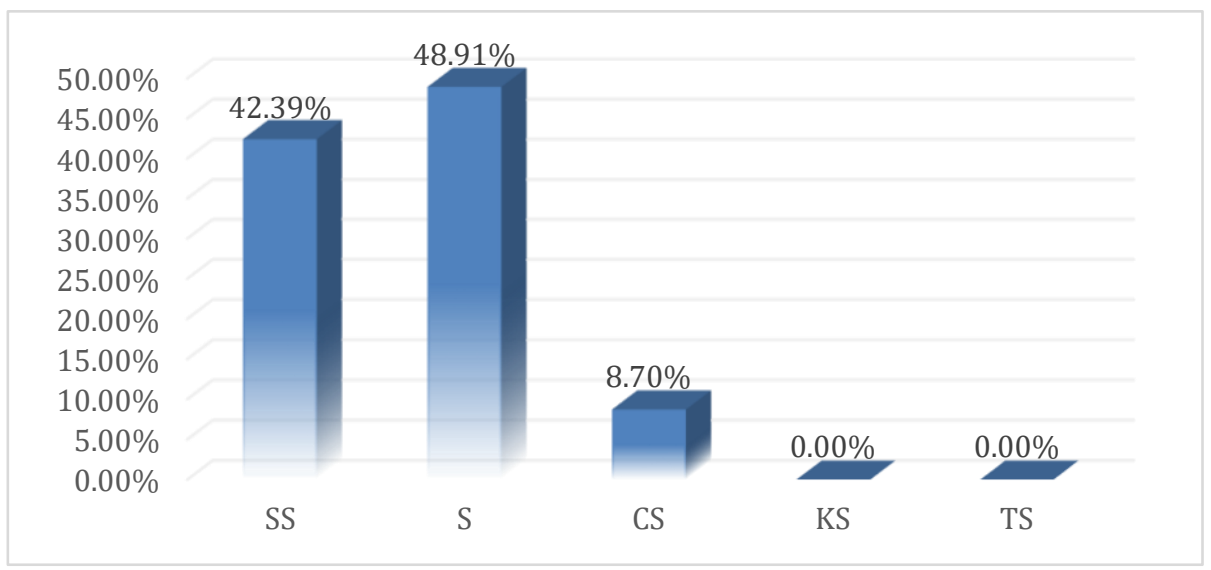

Gambar 1 Tanggapan peneliti tentang pustakawan yang memiliki pendidikan dan keterampilan tentang kepustakawanan

Pada poin ini dilihat berapa persentase mahasiswa yang menyetujui bahwa pustakawan memiliki pendidikan dan keterampilan tentang kepustakawanan. Ada pun butir pertanyaan yang diberikan adalah pustakawan memberikan jasa pelayanan kepada mahasiswa yang 
membutuhkan buku dan karya ilmiah yang digunakan dalam pembelajaran; pustakawan bersikap ramah terhadap mahasiswa yang mencari buku dan karya ilmiah yang digunakan dalam pembelajaran; Pustakawan memberikan bantuan ketika mahasiswa mengalami kesulitan dalam mencari buku dan karya ilmiah yang digunakan dalam pembelajaran; Pustakawan mampu memberikan informasi tentang posisi/status buku dan karya ilmiah yang dicari mahasiswa.

2. Memiliki Keterampilan Pemanfaatan Teknologi Informasi

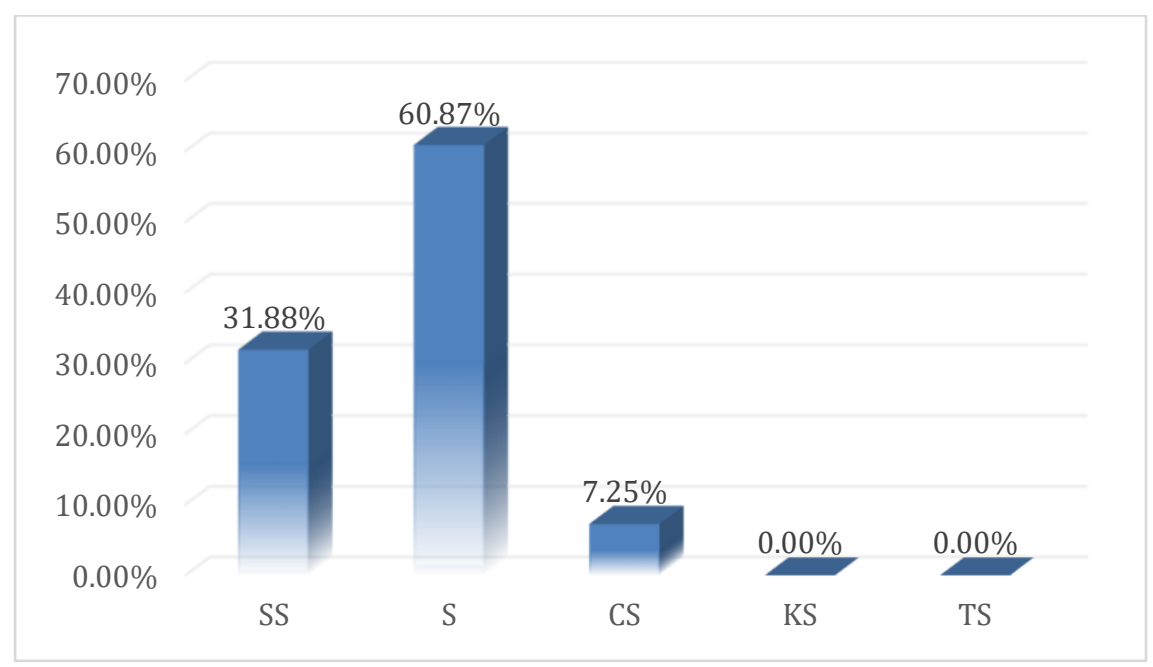

Gambar 2 Tanggapan peneliti tentang pustakawan yang memiliki keterampilan pemanfaatan teknologi informasi

Pada poin ini dilihat berapa persentase mahasiswa yang menyetujui bahwa pustakawan memiliki keterampilan pemanfaatan teknologi informasi. Ada pun butir pertanyaan yang diberikan adalah Pustakawan memiliki keterampilan dalam mengoperasikan komputer yang tersedia di perpustakaan; Pustakawan membantu mahasiswa dalam menggunakan katalog online untuk menemukan buku dan karya ilmiah yang digunakan dalam pembelajaran; Pustakawan memberikan layanan sirkulasi sesuai dengan teknologi yang disediakan. 
3. Memiliki Ketrampilan Bahasa

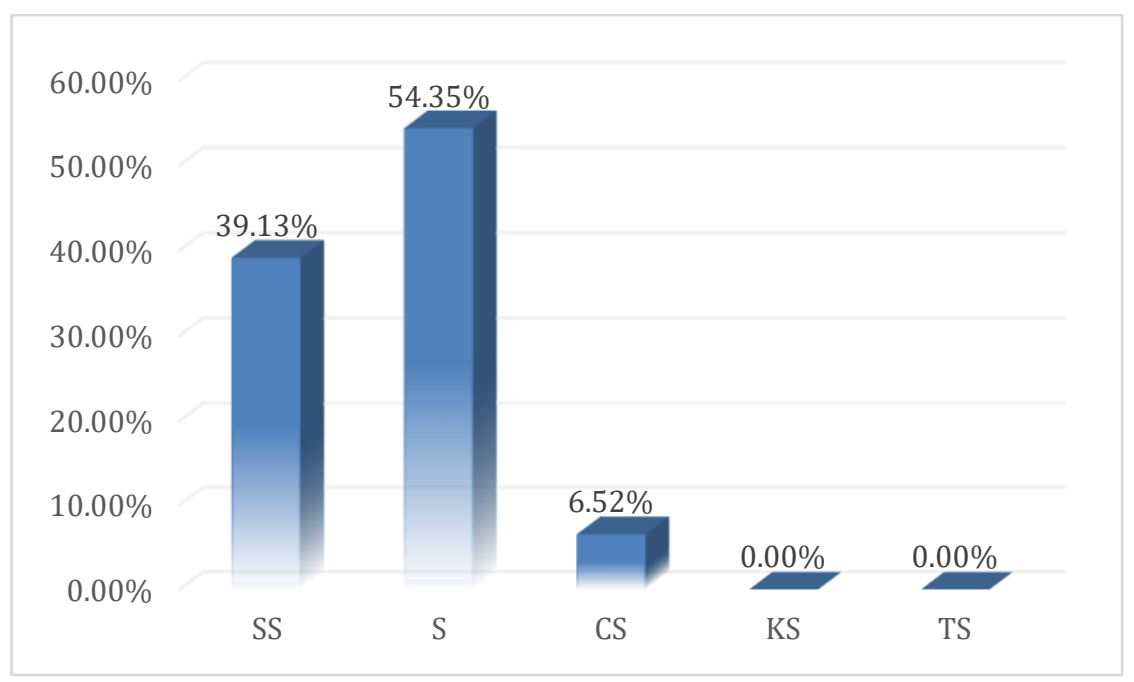

Gambar 3 Tanggapan peneliti tentang pustakawan yang memiliki keterampilan berbahasa

Pada poin ini dilihat berapa persentase mahasiswa yang menyetujui bahwa pustakawan memiliki keterampilan berbahasa. Ada pun butir pertanyaan yang diberikan adalah Pustakawan memiliki keterampilan berkomunikasi yang baik; Pustakawan bersikap sopan dan ramah kepada pengunjung

4. Mengetahui Kebutuhan Pemustaka

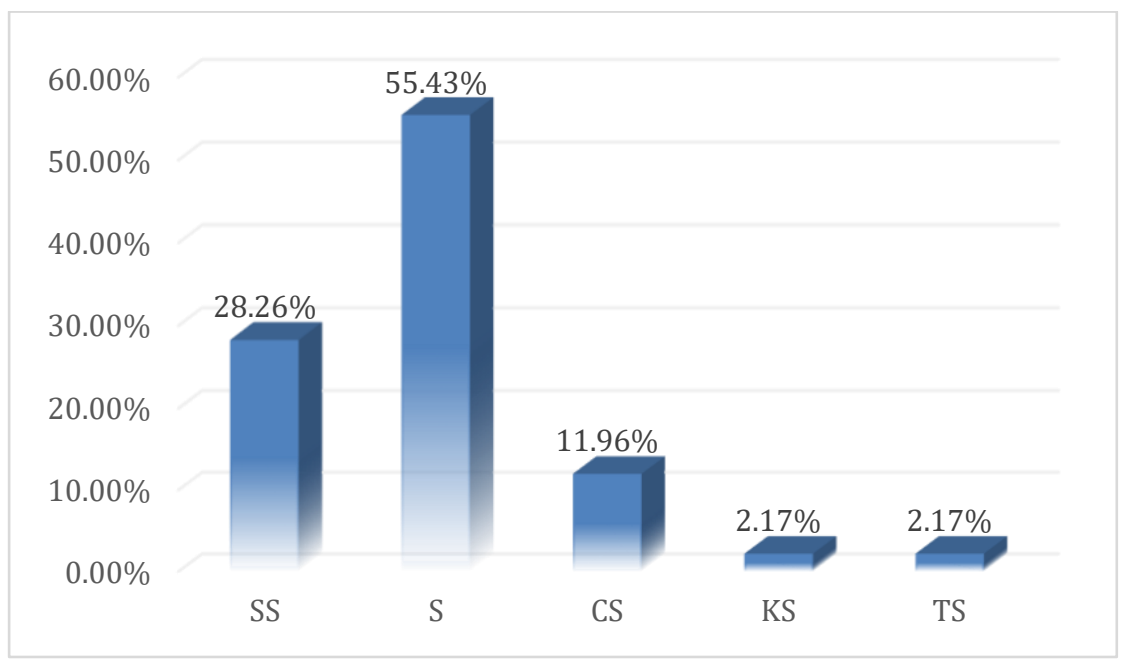

Gambar 4 Tanggapan peneliti tentang pustakawan yang mengetahui kebutuhan pemustaka 
Pada poin ini dilihat berapa persentase mahasiswa yang menyetujui bahwa pustakawan mengetahui kebutuhan pemustaka. Ada pun butir pertanyaan yang diberikan adalah Pustakawan menampung saran/masukan untuk pengadaan buku dan karya ilmiah yang dicari oleh mahasiswa namun tidak tersedia di perpustakaan; Pustakawan mencari informasi buku dan karya ilmiah apa saja yang dibutuhkan mahasiswa dalam pembelajaran; Pustakawan mengadakan survei kebutuhan dan kelengkapan buku dan karya ilmiah yang digunakan dalam pembelajaran; Pustakawan memberikan kelancaran dalam menemukan buku dan karya ilmiah yang digunakan dalam pembelajaran.

5. Sense of Media

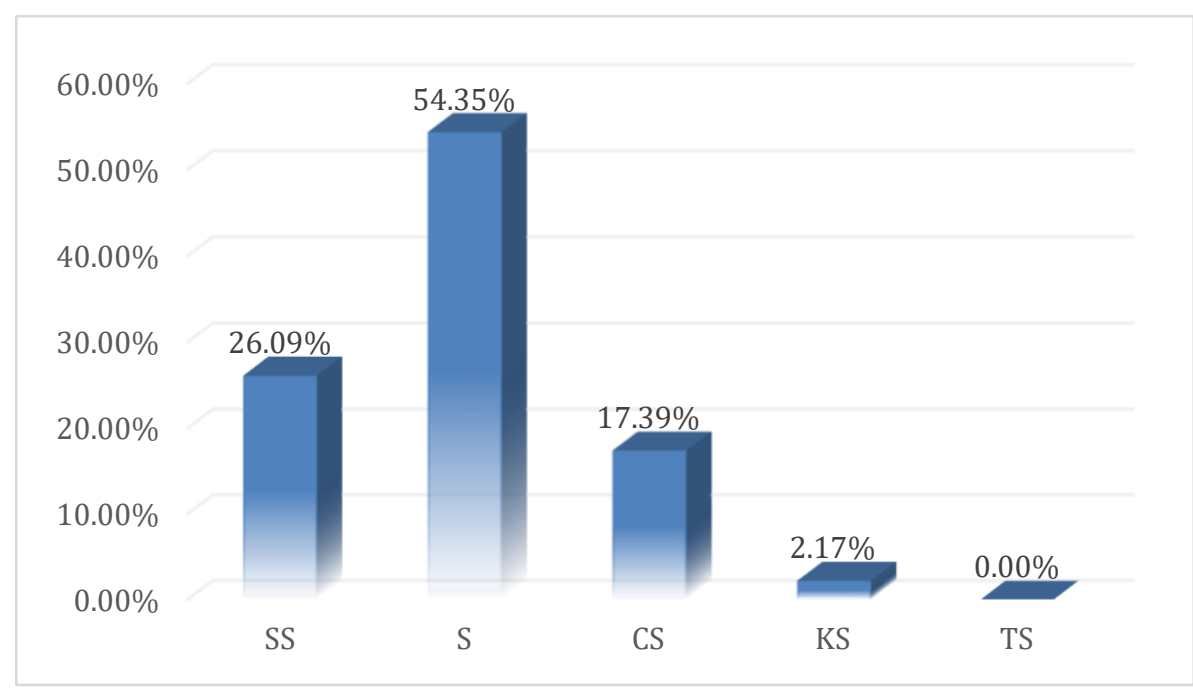

Gambar 5 Tanggapan peneliti tentang pustakawan yang memiliki sense of media

Pada poin ini dilihat berapa persentase mahasiswa yang menyetujui bahwa pustakawan memiliki sense of media. Ada pun butir pertanyaan yang diberikan adalah Pustakawan peka dan mengetahui terhadap adanya media-media terbaru seperti ebook, jurnal online, dan media lainnya yang berguna sebagai referensi dalam pembelajaran; Pustakawan mengetahui dan memberikan informasi tentang media-media cetak diperpustakaan dan informasi apa yang ada di dalamnya

Secara keseluruhan, efektivitas Peran pustakawan sebagai sumber pustaka dalam penelitian dapat dilihat pada diagram berikut: 
152 | Mariatul Qibthiyyah: Efektivitas Peran Pustakawan...

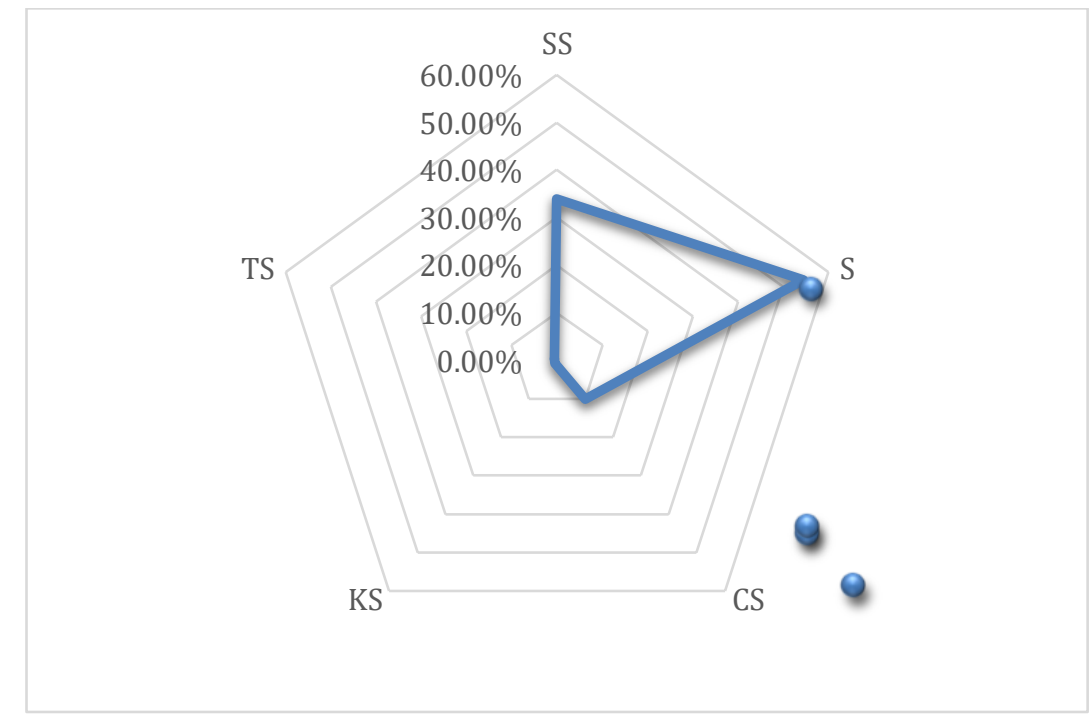

Gambar 6 Tanggapan peneliti tentang efektivitas peran pustakawan sebagai teman menemukan sumber pustaka

Grafik tersebut menunjukkan bahwa sebagian besar peneliti, yakni $54,49 \%$ peneliti setuju bahwa pustakawan efektif sebagai teman menemukan sumber pustaka untuk penelitian. 33,91\% peneliti manyatakan sangat setuju. Sementara sebagian kecil peneliti yakni $0,87 \%$ dan $0,58 \%$ peneliti secara berturut-turut menyatakan bahwa peneliti kurang sependapat dan bahkan tidak sependapat dengan apa yang dinyatakan dalam kuisioner

Hasil ini sesuai dengan tugas dari Pustakawan ULM yakni meyediakan fasilitas untuk menunjang tridharma pendidikan, diantaranya adalah penelitian. Pustakawan harus menjadi fasilitator yang memudahkan dalam penelitian (Rizki, 2013; Suharso et al., 2020). Pustakawan memberikan pelayan yang efektif agar secara simultan mendukung jalannya misi universitas (Nugrohoadhi, 2017). Penelitian sebelumnya juga dilakukan tentang bagaimana peranan pustakawan dalam mendukung pendidikan yang merupakan salah satu tridharma perguruan tinggi. Dengan demikian, hasil yang diperoleh dalam penelitian ini menunjukkan bahwa pustakawan ULM telah mengambil peranan dalam mendukung jalannya tridharma perguruan tinggi, diantaranya adalah pendidikan dan penelitian. 


\section{KESIMPULAN}

Menjawab rumusan masalah, yakni bagaimana efektivitas pustakawan sebagai mitra pemustaka dalam menemukan sumber pustaka untuk penelitian, disimpulkan bahwa peran pustakawan telah efektif sebagai mitra menemukan sumber pustaka untuk penelitian.

\section{DAFTAR RUJUKAN}

Asmad, C. C., \& Mathar, T. (2015). Peran Pustakawan dalam Meningkatkan Kinerja Perpustakaan. Khazanah Al-Hikmah, 3(2). https://doi.org/https://doi.org/10.24252/kah.v3i2a1

Azwar, M., \& Kaharuddin. (2016). Peranan perpustakaan sekolah dalam mendukung kurikulum tingkat satuan pendidikan (KTSP) Di SMA Negeri 1 Sinjai Tengah. Safina, 1(2), 11-26. http://journal.staimidepok.ac.id/index.php/safina/

Hapsari, D. (2017). Optimalisasi layanan penelusuran sumber-sumber informasi untuk mendukung penulisan karya ilmiah dosen dan mahasiswa di perguruan tinggi. Jurnal Pustaka Ilmiah, 2(1), 117-121.

Istiana, P. (2019). Peran Luas Pustakawan dalam Mendukung Visibilitas Publikasi Institusi Berkelanjutan. Media Pustakawan. https://doi.org/https://doi.org/10.37014/medpus.v24i3.229

Johan, T. M., \& Ahmalia, R. (2019). Penilaian Mutu Dosen terhadap Tri Dharma Perguruan Tinggi dengan Menerapkan Logica Fuzzy Logic di STIKES Nan Tongga. Jurnal Akademika Baiturrahim Jambi, 8(2), 175182.

Kurniawati, A., \& Setyadi, A. (2019). Kontribusi Pustakawan Referensi UPT Perpustakaan Dalam Mendukung Penelitian di Universitas Diponegoro. Jurnal Ilmu Perpustakaan, 8(4), 171-180.

Kurniawati, N., Mustafa, B., Ardiansyah, F., \& Mulyani, E. S. (2012). Pemodelan konsep fundamental repositori institusi di Perpustakaan Universitas Sultan Ageng Tirtayasa dengan menggunakan framework zachman. Jurnal Perpustakaan Pertanian, 21(2), 35-44. http://repository.pertanian.go.id/handle/123456789/2182

M.Reza Rokan. (2017). Manajemen perpustakaan sekolah. Jurnal Iqra', 11(01), 1-14. https://doi.org/http://dx.doi.org/10.30829/iqra.v11i01.795

Mujab, A. I., Setyadi, A., \& Rukiyah. (2015). Persepsi Pemustaka Terhadap Sikap Pustakawan dalam Layanan Referensi di Perpustakaan Universitas Katolik Soegijapranata. Jurnal Ilmu Perpustakaan, 4(2), 17. https://ejournal3.undip.ac.id/index.php/jip/article/view/9513 
Nugrohoadhi, A. (2017). Strategi perpustakaan dan peningkatan kompetensi pustakawan dalam mendukung tri dharma perguruan tinggi. Bibliotech: Jurnal Ilmu Perpustakaan Dan Informasi, 2(1). https://doi.org/https://doi.org/10.33476/bibliotech.v2i1.868

Peraturan Kepala Perpustakaan Nasional Republik Indonesia Nomor 11 Tahun 2015 Tentang Petunjuk Teknis Jabatan Fungsional Pustakawan Dan Angka Kreditnya, (2015).

Prabowo, A. (2018). Peran Pustakawan UPT Perpustakaan Dian Nuswantoro dalam Literasi Layanan Turnitin Kepada Dosen dan Mahasiswa di Universitas Dian Nuswantoro. LIBRARIA: Jurnal Perpustakaan, 6(2), 419-438.

Qibthiyyah, M. (2020). Peran pustakawan sebagai teman karib (tempat efektif menemukan aneka referensi ilmiah dan buku) dalam $\begin{array}{lll}\text { pembelajaran. } & \text { Pustakaloka, }\end{array}$ https://doi.org/https://doi.org/10.21154/pustakaloka.v12i2.2239

Rizki, J. W. S. (2013). Optimalisasi Fungsi Perpustakaan Perguruan Tinggi Melalui Peran Pustakawan Juni Wati Sri Rizki $\square$. Al-Kuttab, Vol. 1, No. 2, Juli - Desember 2013 Fasilitas1., 1(2), 105-117. http://repo.iainpadangsidimpuan.ac.id/377/

Simanjuntak, S. T., \& Wahyanti, C. T. (2021). Analisis Kinerja Dosen Melaksanakan Tri Dharma Perguruan Tinggi Pada Masa Pandemi Covid-19: Studi Kasus Di Universitas Kristen Satya Wacana. JENIUS (Jurnal Ilmiah Manajemen Sumber Daya Manusia), 5(1), 86-101.

Suharso, P., Arifiyana, I. P., \& Wasdiana, M. D. (2020). Layanan perpustakaan perguruan tinggi dalam menghadapi pandemi covid-19. Anuva, $4(2)$, 271-286. https://ejournal2.undip.ac.id/index.php/anuva/article/view/8185/4303

Suryani, T. (2018). Penguatan Peran Perguruan Tinggi Dalam pemberdayaan masyarakat di era industri 4.0. Seminar Nasional Hasil Pengabdian Kepada Masyarakat (SENIAS), 2013, 1-6. http://senias.uim.ac.id/index.php/senias_2017/article/view/123

Suwena, K. R. (2012). Menciptakan Layanan Perpustakaan Yang Berkualitas Sebagai Pendukung Pelaksanaan Tri Dharma Perguruan Tinggi. Media Komunikasi FIS, 11(23), 16-29. https://doi.org/http://dx.doi.org/10.23887/mkfis.v11i1.451 